\title{
Theoretical Model of User Acceptance: In the View of Measuring Success in Web Personalization
}

\author{
Mohd Afandi Md Amin and Richi Nayak \\ Faculty of Science and Technology, \\ Queensland University of Technology, \\ Brisbane, Australia \\ mohd.mdamin@student.qut.edu.au, r.nayak@qut.edu.au
}

\begin{abstract}
This paper attempts to develop a theoretical acceptance model for measuring Web personalization success. Key factors impacting Web personalization acceptance are identified from a detailed literature review. The final model is then cast in a structural equation modeling (SEM) framework comprising nineteen manifest variables, which are grouped into three focal behaviors of Web users. These variables could provide a framework for better understanding of numerous factors that contribute to the success measures of Web personalization technology. Especially, those concerning the quality of personalized features and how personalized information through personalized Website can be delivered to the user. The interrelationship between success constructs is also explained. Empirical validations of this theoretical model are expected on future research.
\end{abstract}

Keywords: Web personalization, measuring success, adoption, measures.

\section{Introduction}

Information overload [1], [2], and [3] is a degree of complexity information processing by the user in most collaboration technologies, as well in Web environment. The overload problem is resulting from the diffusion of the Web and the huge amount of information available online [4], and [5], since users have to find relevant, needed, useful and personalized information. Thus, the problem has given advance to the compelling required for Web systems able to assist users intelligently, when they browse through the Web. Web personalization offers this precious opportunity, representing one of the most influential technologies required by an ever increasing number of real-world applications. Consequently, Web personalization is momentous research issue in Web applications, as well as has been a key property for online news providers, ecommerce Websites, and technical data providers.

In addition, measuring success or effectiveness of the Web personalization system involves the defining metrics and feedback techniques, from two endeavour; computational intelligence (CI) and Information systems (IS). CI revealed on computational approaches that employed several algorithms and techniques [4], Whereby, IS focusing on the user's behavior of the systems that based-on the theoretical foundation 
from diverse disciplines such as psychology, computer sciences, business and statistics. Furthermore, IS studies remain on user's behavior of the Web personalization systems such as whether online firms can use personalization as a marketing strategy to attract new users [6], [7], and [8], personality traits and perception towards the influence of user's behavior on the Website.

This paper is structured as follows. Firstly, the theoretical underpinning used to develop the model is presented. The four prominent theories of measuring success are examined: DeLone and McLean Information Success model (IS-success), theory of acceptance Model (TAM), theory of planned behavior (TPB), and Unified theory of Acceptance and Use Technology (UTAUT). Then the possibilities of success measures in Web personalization are presented from those theories. Secondly, the TPB is preferred to be a framework for measuring success in Web personalization, followed by methodology to be used in the future research. Finally, we provide a discussion of the findings and the agenda for future research.

\section{Measuring Success in Web Personalization}

Websites today, have access to the incredible amount of data about the visitors and users to their Websites, the preferences and their behavior [9], [10], and [11]. There are numbers of different approaches and architectures has been employed in building support for such personalization systems, each of which has different strengths and weaknesses [12],[10], and [13].

The need for measuring success of the Web personalization is not only beneficial for vendors or providers but also has been remarkable to the users. For instance, the vendors need to know how success or effective their delivered personalized features on the Web, while feedback from the users can be an input for vendors to enhance their personalized services through Website. In a same way, the adoptions of personalized services by the users are also crucial, in terms of personalization strategies, especially for online vendors.

\subsection{The Significance of Measuring Success}

In this section, we define how measuring success in Web personalization is crucial from three perspectives: (1) the developers, (2) the Website owner, and (3) the user. Effective Web personalization has become a prominent issue due to the pervasiveness of e-commerce applications [14], [15], and [16]. Most of the Web services have multiple stakeholders, for example, developers, users and investors. Therefore, measuring success or effectiveness of the services has also multiple definitions from several views. For developers, success of the services may be one is completed in time or within the budget, with a complete set of features that are consistent with predefined specification and that functions correctly. On the other hand, from a Website owner, success for them is if the personalization services can reduce uncertainty outcomes, attracts a large, loyal and growing community of users. Additionally, the effective contents can be gained if the right person receives the right message at the right time and the right context [17]. In contrast, for users success is if personalization services able to improve their task and easy to use. 
There is much significance of measuring success in Web personalization. Particularly, we summarize the significance of measuring success of Web personalization by considering of generalizing the adoption, implementation and the use of personalization techniques as presented in Figure 1 below.

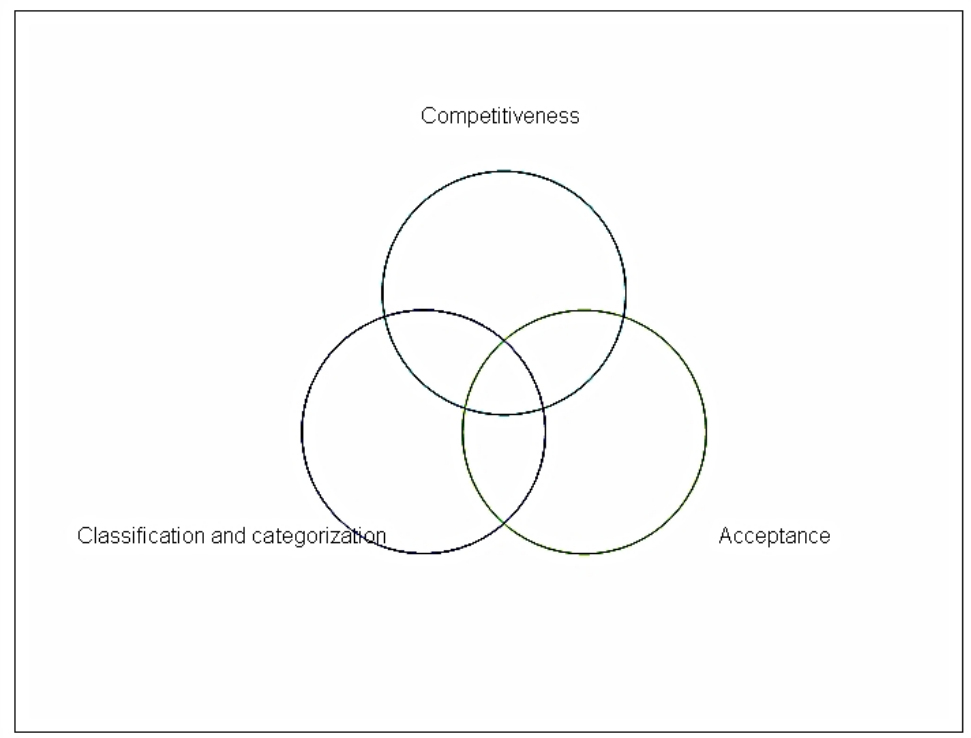

Fig. 1. Effectiveness of Web personalization

From the Figure 1, the significance of measuring success of Web personalization is proposed in three components:

\subsubsection{The Ability to Classify and Categorize the Popular Features of the Website}

The ability for classification and categorization of popular features is one of the most salient aspects to determine whether or not enterprises implement the Web personalization system [18]. It depends on personalization features on the Website, for example, the more personalization features will lead the effective personalization agent for classify and tailoring the contents or products to suit with user's preferences from user profile, explicit and implicitly. In terms of cost, the more sophisticated of personalized agents will increase the cost that needs to be allocated by the enterprises or Website owner. Therefore, measuring success is vital to acknowledge enterprises about the effectiveness of the personalized system and related with the cost benefit analysis.

Many studies have been conducted on measuring these features, which categorized in computational intelligence $(\mathrm{CI})$ research. CI paradigms reveal to be potential tools to face under Web environment, which handle Web usage data and develop Webbased applications tailored on users' preferences [4]. Recently, classification and categorization of the usage data as well as Web contents, has been studied under the application of data mining techniques for Web data, namely Web mining. The most popular techniques have been used is clustering [4]. Clustering techniques look for a group of similar items among huge of data base on a general idea of distance. This technique computes the similarity between items [19]. 


\subsubsection{The Competitiveness of the Website Provider}

Measuring success in Web personalization, particularly in most e-commerce Websites is noteworthy since it reflects the competitiveness of the enterprises. E-commerce mainly focused on the sale of goods and with the advent of Web technology, it has been expanded to deal with all aspects of business interaction, at the individual and enterprise level. In terms of cost benefit analysis, the more competitive the market structure, the complicated the decision of whether or not to implement a personalization strategy, or proceed with the current personalization strategy on the Website. If the personalization strategy is not successful then the enterprises could suffer severe damage, in such having a negative value of the return of investment (ROI).

The studies revealed in comparing personalization strategy and marketing prospect, falls in marketing research, since personalization is the process of gathering information explicitly or implicitly about customer or user, which enable the enterprise to target products or recommendations that best match the user's preferences [20]. Research shows that the Web is particularly suited for personalized services [21] compare to other media (e.g. newspapers and television). For instance, recent empirical evidence indicates that about $80 \%$ of Internet users are interested in personalized services [22], a well as $56 \%$ of frequent online shoppers were more likely to make a purchase on a Website that offered personalization features [23].

\subsubsection{Acceptance and Use of Web Personalization by the User}

Acceptance refers to how users accept and favor the personalization features through personalization systems. The acceptance Web personalization by the user is needed to be measured, since it indicates to what extent that the personalization systems are use and continuing use by the user. Although the success evaluation is necessary, however, it is difficult to measure, since it is influenced by various factors such as customer usage, customer skills, and ease of use of the systems as well as usefulness of the systems.

Evaluation or measuring success can also be viewed as effectiveness and impact of the system that perceived by the users. According to [24], such evaluation of the system is based on design science research. Therefore, it concerns about evaluation of outputs, including theory and artefacts.

\section{Theoretical Underpinning of Measuring Success}

In this section, we introduce four prominent theories and model in Information Systems (IS) research for measuring success: IS-success model, theory of acceptance model (TAM), and theory of planned behavior (TPB), and unified theory of acceptance and use of technology (UTAUT).

\subsection{Information Success Model (IS-Success)}

The first theory examine is the Information Systems success model (IS-success), The IS-success model was the comprehensive IS success model for measuring IS-impact and has been introduced by [25], as a success framework with complex-dependent variables in IS research. The model shows an interrelationship between six IS success variables categories namely: (1) system quality, (2) information quality, (3) IS use, (4) user satisfaction, (5) individual impact, and (6) organization impact. 


\subsection{Technology Acceptance Model (TAM)}

The second theory examine is technology acceptance model (TAM). The TAM was introduced by [26], is an outgrowth of the model of individual behavior as posited by [27], theory of Reasoned Action (TRA) and Theory of Planned Behavior (TPB), which showed the influence of the perceived ease of use and the perceived usefulness of a technology on the user's attitudes toward using the technology and subsequently on the actual usage thereof.

\subsection{Theory of Planned Behavior (TPB)}

Next, the TPB is examined. TPB is an extension of theory reasoned action (TRA) is the most influential theory in explaining and predicting behavior. The theory of planned behavior is one of the most influential theories in projecting human behavior across many settings [28] and has been validated by prior research. According to $\mathrm{TPB}$, the direct root of any Behavior is its Behavioral Intentions; after all, people do what they plan to do. Behavioral intention is defined as "the strength of one's intention to perform a specified behavior [27]. According to [28], "human action is guided by three kinds of considerations: beliefs about the likely outcomes of the behavior and evaluations of these outcomes (behavioral beliefs), beliefs about the normative expectations of others and motivation to comply with these expectations (normative beliefs), and beliefs about the presence of factors that may facilitate or impede performance of the behavior and the perceived power of these factors (control beliefs)". Figure 2 below described the TPB.

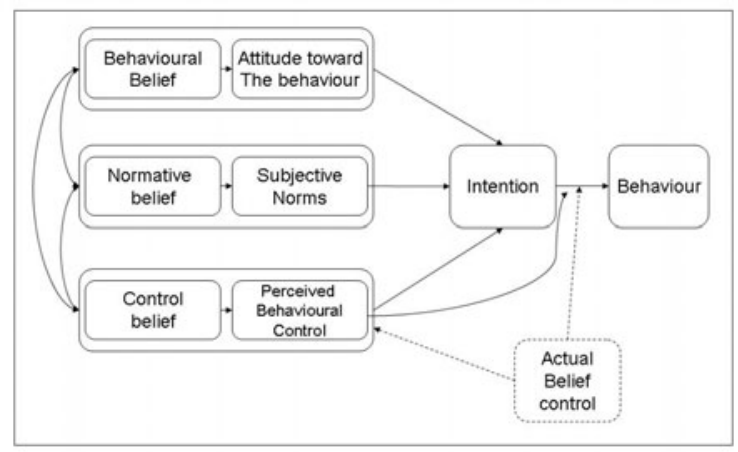

Fig. 2. The constructs of TPB [28]

\subsection{Unified Theory of Acceptance and Use of Technology (UTAUT)}

Finally, the composed model that integrated theories and model from unified view of user acceptance is examined. The latest work proposed by [7] integrates eight models from fragmented view to unified view that collaborated the major theories and models in user acceptance. Instead of three theories that have been discussed above, UTAUT utilized the following models: the Theory of Reasoned Action (TRA), the model of PC Utilization (MPCU), the motivation models (MM), the Innovation and Diffusion 
Theory (IDT), and Social Cognitive Theory (SCT). In UTAUT, there are four antecedents used to describe user acceptance toward technology: performance expectancy (PE), effort expectancy (EE), social influence (SI), and facilitating conditions (FC). Four moderators i.e. gender, age, experience, and voluntaries of use are employed to describe various relationships between antecedents and behavioral intentions (BI), for example, gender are expected to have influences in PE, EE, and SI. Whereby, age expected to influence in all four antecedents.

\section{Theoretical Model and Methodology}

\subsection{TPB as a Framework}

From the four theories that defined success, TPB has been chosen as a framework for constructing the Web personalization success model. There are some reasons to select the TPB for the theoretical framework among other success theories. Firstly, the TPB has three elements that defined the cause toward user's behavior on the system: (a) attitude toward behavior, (b) subjective norms, and perceived behavioral control. These three elements described the behavior of the users toward intention to use of the Web personalization system. The first element described the idea that by using the personalization will increase performance of the user on the Website e.g. finding information, products, or articles. This feeling of the users will lead attitude to use the system. Secondly, subjective norms are related to user's decision on the system will be affected by other user's opinion to use personalization, and last element, perceived behavioral control defined by perception about how personalization system work as well as it depends on other factors such as time, experience, security and privacy manners that influence the use of personalization system by the users.

Thirdly, it was selected because it shows the relationships of the success measures of Web personalization, since we argue that success is multidimensional phenomenal of a user using a personalized Website, where they engage in a complex set of behavior in three behavioral intentions between acquiring information from a Website, giving information to a Website, and navigating through a Website. These multidimensional construct views are also agreed with the previous research on measuring success in several areas such as business modeling [29], and Information systems $[30],[31],[32],[33],[34],[35],[36],[37]$, and [38].

\subsection{Methodology}

We expect a positive relationship for the three focal behaviors of Web users: (1) acquiring information, (2) giving information, and (3) navigating on the personalized Website. From the previous study, we argue that the effect of web personalization to the users are also related to personality traits on choice behavior [39], [40], and [6], which described how users interact with transaction driven personalization. In order to identify antecedents of web personalization adoption TPB is used. According to [41] and [28], the antecedents of attitudes, subjective norm, Perceived Behavioral Control (PBC) is a set of attitudinal, normative and control belief, respectively. However, normative beliefs were dropped due to it only specify the referent others (e.g. family, friends, or society), which is believed will not influence a user's attitude and 
control toward using Web personalization. Additionally, other researchers argued that in the context of using technologies, subjective norms did not seem to be a significant predictor of intentions [26, 42].

Moreover, several studies on the e-commerce Website have excluded subjective norms, focusing only on ease of use and usefulness. They argued that intention of browsing and use applications by an individual is not impacted from other individuals. This agree with finding about browsing a particular Website (e.g. personalized Website) is a private affair and not visible to peers or friends. Peers or friends influence might impact on Website in general, but not to revisit a Website. Thus, in this study, subjective norms are excluded to have influence in behavioral intentions of use a personalized Website.

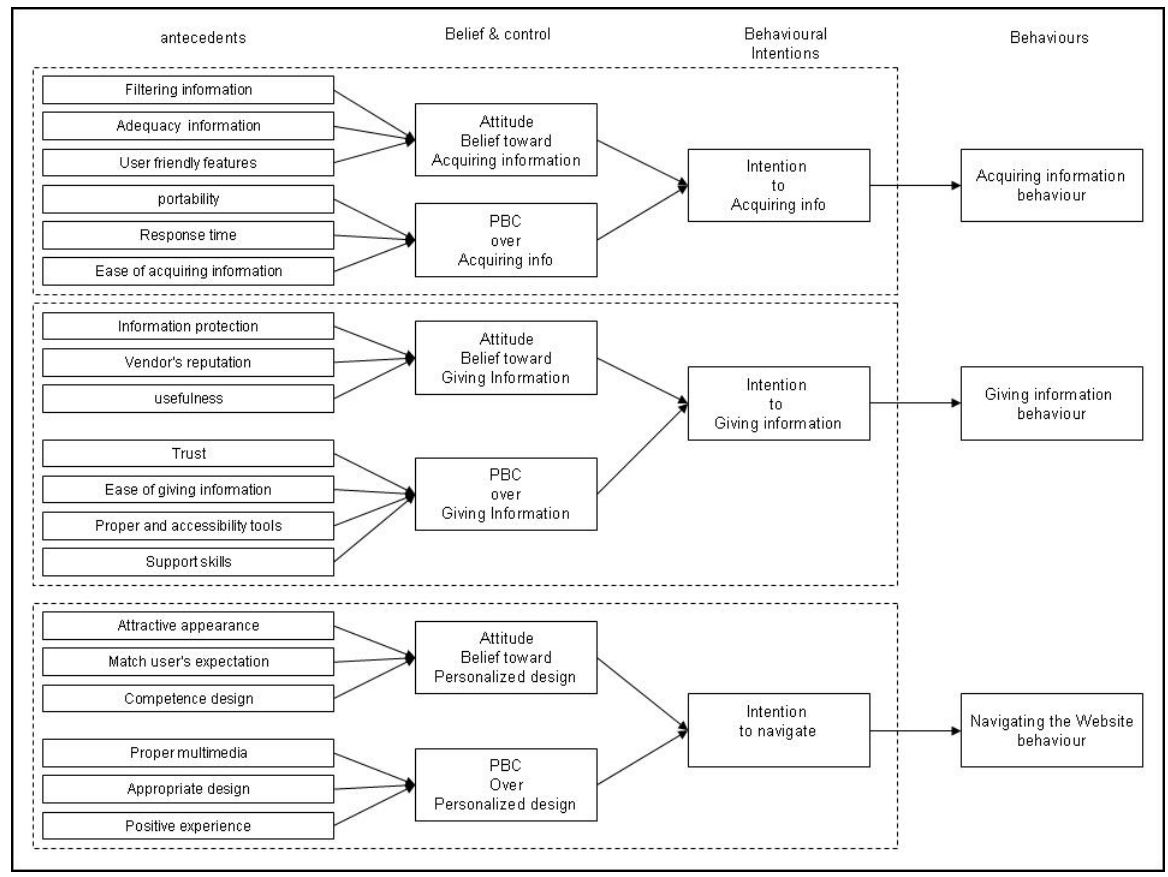

Fig. 3. Web personalization success model

Therefore, the Web personalization success model is proposed in Figure 3, as an extension of TPB. The model extends TPB from three focal user's behavior: acquiring information from personalized Website, giving information, and perceived on personalized designed.

As depicted in Figure 3, the success constructs are defined in antecedents' part, where belief and control, intentions, and user's behaviors are presented on the right side, respectively. There are nineteen (19) antecedents of success have been defined in three user's focal behavior dealing with personalized Website

According to the relationship between variables, the corresponding hypotheses among all variables will be developed. Then we further study the meaning of all 
variables and develop measurement scales for each variable. Once the full model testing is complete, the structural equation modeling (SEM) will be used to define the reliability and validity of the proposed model, particularly, by employing the partial least square path modeling (PLS-PM) for the structural and measurement model.

We summarized the success measures in Web personalization as presented in Figure 3 , in Table 1 below:

Table 1. Success Measures

\begin{tabular}{|c|c|c|}
\hline User's focal behavior & Constructs & Success Measures \\
\hline \multirow[t]{2}{*}{ Acquiring information } & Attitude belief & $\begin{array}{l}\text { Information filtering } \\
\text { Intrusiveness } \\
\text { User-friendly features }\end{array}$ \\
\hline & $\begin{array}{l}\text { Perceived behavioral } \\
\text { control }\end{array}$ & $\begin{array}{l}\text { Portability } \\
\text { Response time } \\
\text { Ease of acquiring information }\end{array}$ \\
\hline \multirow[t]{2}{*}{ Giving information } & Attitude belief & $\begin{array}{l}\text { Information protection } \\
\text { Vendor's reputation } \\
\text { Usefulness of giving information }\end{array}$ \\
\hline & $\begin{array}{l}\text { Perceived behavioral } \\
\text { control }\end{array}$ & $\begin{array}{l}\text { Trust } \\
\text { Ease of giving information } \\
\text { Proper and accessibility tools } \\
\text { Support skills }\end{array}$ \\
\hline \multirow[t]{2}{*}{ Personalized design } & Attitude belief & $\begin{array}{l}\text { Attractive appearance } \\
\text { Match user's expectation } \\
\text { competence }\end{array}$ \\
\hline & $\begin{array}{l}\text { Perceived behavioral } \\
\text { control }\end{array}$ & $\begin{array}{l}\text { Proper multimedia capability } \\
\text { Appropriate design } \\
\text { Positive experience }\end{array}$ \\
\hline
\end{tabular}

\section{Conclusions and Future Research}

Web personalization is a prominent approach for tailoring user's need on the Web, since due to the uncertainty of information on the Web. This research is going to improve and define the recognition of user acceptance behavior by advancing and validating the theoretical model of measuring success in Web personalization.

The study postulates success measures in Web personalization, particularly from human contributions through user's acceptance and adoption of Web personalization technology. Therefore, this theoretical model can help personalized Web developers to define their strategy on delivering personalized information on the Web. This strategy is based on three user's focal behavior: acquiring information through personalized Website, giving personal details on the personalized Website (e.g. filling online form for registration on ecommerce Website), and navigating through personalized Website. The success strategy is reflected by good personalized design, including proper multimedia capability applications, competence and professional design, and as well as the personalized design match user's expectation about personalized information. In the future, all defined measures will be constructed in the form of survey questionnaires. 


\section{References}

1. Kosala, R., Blockeel, H.: Web Mining Research: A Survey. In: SIGKDD Explorations: Newsletter of the Special Interest Group (SIG) on Knowledge Discovery \& Data Mining (2000)

2. Paul, S., Nazareth, D.L.: Input information complexity, perceived time pressure, and information processing in GSS-based work groups: An experimental investigation using a decision schema to alleviate information overload conditions. Decision Support Systems, Corrected Proof (2010) (in Press)

3. Wheeldon, R., Levene, M., Keenoy, K.: Search and Navigation in Relational Databases (2003)

4. Castellano, G., Fanelli, A.M., Torsello, M.A.: Computational Intelligence techniques for Web personalization. Web Intelligent and Agent System 6, 253-272 (2008)

5. Castellano, G., Fanelli, A.M., Torsello, M.A., Jain, L.: Innovations in Web Personalization: Web Personalization in Intelligent Environments, pp. 1-26 (2009)

6. Ho, S.Y., Michael, J.D., Tam, K.Y.: Personalization and choice behavior: the role of personality traits. SIGMIS Database 39, 31-47 (2008)

7. Venkatesh, M., Morris, K., Davis, F.: User acceptance of information technology: Toward a unified view. MIS Quarterly 27, 425-478 (2003)

8. Venkatesh, M., Ramesh, K.: Web and Wireless Site Usability: Understanding Differences and Modeling Use. MIS Quarterly 30, 181-206 (2006)

9. Avery, C., Zeckhauser, R.: Recommender systems for evaluating computer messages. Communications of the ACM 40, 88-89 (1997)

10. Peyton, L.: Measuring and managing the effectiveness of personalization. In: Proceedings of the 5th International Conference on Electronic Commerce Pittsburgh. ACM, Pennsylvania (2003)

11. Shearin, S., Lieberman, H.: Intelligent profiling by example. In: Proceedings of the 6th International Conference on Intelligent User Interfaces, Santa Fe, New Mexico, United States, pp. 145-151 (2001)

12. Paganelli, L., Paterno, F.: Intelligent analysis of user interactions with web applications. In: Proceedings of the 7th International Conference on Intelligent user Interfaces. ACM, San Francisco (2002)

13. Scholtz, J., Laskowski, S., Downey, L.: Developing usability tools and techniques for designing and testing web sites. In: Proceedings HFWeb 1998, Basking Ridge, NJ (1998)

14. Goy, A., Ardissono, L., Petrone, G.: Personalization in E-Commerce Applications. In: The Adaptive Web, pp. 485-520 (2007)

15. VanderMeer, D., Kaushik, D., Anindya, D., Krithi, R., Shamkant, B.N.: Enabling scalable online personalization on the Web. In: Proceedings of the 2nd ACM Conference on Electronic Commerce Minneapolis. ACM, Minnesota (2000)

16. Yu, P.S.: Data Mining and Personalization Technologies. In: Proceedings of the Sixth International Conference on Database Systems for Advanced Applications. IEEE Computer Society, Los Alamitos (1999)

17. Kazienko, P., Adamski, M.: AdROSA- Adaptive personalization of Web advertising. International Journal of Information Sciences 177, 2269-2295 (2007)

18. Greer, Murtaza: Web personalization: the impact of perceived innovation characteristics on the intention to use personalization. Journal of Computer Information Systems 43, 50 55 (2003)

19. Vakali, A., Pokorny, J., Dalamagas, T.: An overview of web data clustering practices. In: Lindner, W., Mesiti, M., Türker, C., Tzitzikas, Y., Vakali, A.I. (eds.) EDBT 2004. LNCS, vol. 3268, pp. 597-606. Springer, Heidelberg (2004) 
20. Nunes, P.F., Kambil, A.: Personalization? No Thanks. Harvard Business Review (2001)

21. Risch, D., Schubert, P., Leimstoll, U.: Classification of Personalization Functions for E-Commerce Applications. In: CollECTeR Adelaide (2006)

22. Kobsa, A.: Privacy-Enhanced Web Personalization. Communiaction of the ACM 30, 24-33 (2007)

23. Freedman, L.: Merchant views of personalization and lasting consumer relationships (2007)

24. Pries-Heje, J., Richard, B., John, V.: Strategies for design science research evaluation. In: Proceedings of the 16th European Conference on Information Systems (ECIS 2008), Ireland (2008)

25. DeLone, W.H., McLean, E.R.: Information Systems Success: The Quest for the Dependent Variable. Information Systems Research 3, 60-95 (1992)

26. Davis, F.D., Bagozzi, R.P., Warshaw, P.: User Acceptance of Computer Technology: A Comparison of Two Theoretical Models. Management Science 35, 982-1003 (1989)

27. Ajzen, I., Fishbein, M.: Attitudinal and normative variables as predictors of specific behavior. Journal of Personality and Social Psychology 27, 41-57 (1973)

28. Ajzen, I.: Perceived behavioral control, self-efficacy, locus of control, and the theory of planned behavior. Journal of Applied Social Psychology 32, 665-683 (2002)

29. Bandara, W.: Process Modeling Success Factors and Measures, in Information Systems. Ph.D Brisbane, Australia: Queensland University of Technology, p. 632 (2007)

30. Bhattacherjee, A.: Understanding Information Systems Continuance: An ExpectationConfirmation Model. MIS Quarterly 25, 351-370 (2001)

31. Davison, J., Deeks, D.: Measuring the potential success of Information Systems Implementation. Journal of Measuring Business Excellent 11, 75-81 (2007)

32. DeLone, W.H., McLean, E.R.: The DeLone and McLean model of information systems success: a ten-year update. Journal of Management Information Systems 19, 9-30 (2003)

33. Gable, G.G., Sedera, D., Chan, T.: Enterprise System Success: A measurement Model. In: Twenty-Fourth International Conference on Information Systems (2003)

34. Ifinedo, P.: Impacts of Business Vision, Top Management Support, and External Expertise on ERP Success. Business Process Management Journal 14, 551-568 (2008)

35. Limayem, M., Cheung, C.M.K.: Understanding information systems continuance: The case of Internet-based learning technologies. Information \& Management 45, 227-232 (2008)

36. Seddon, P., Sandy, S., Ravi, P., Matthew, B.: Dimensions of information systems success. Communications of AIS 2, 5 (1999)

37. Taylor-Cummings, A., Feeny, D.: The development and implementation of systems: bridging the user-IS gap: Managing IT as a Strategic Resource. In: Willcocks, L., Feeny, D., Islei, G. (eds.), pp. 71-202. McGraw Hill, Maidenhead (1997)

38. Wong, B., Arjpu, C.: A Study of How User Satisfaction and User Dissatisfaction Affect the Success of an Information System. In: Australasian Conference on Information Systems, Toowoomba, QLD, pp. 801-812 (2007)

39. Finn, A., Louviere, J.J.: Shopping center patronage models: fashioning a consideration set solution. Journal of Business Research 21, 259-275 (1990)

40. Gensch, D.H.: A Two-Stage Disaggregate Attribute Choice Model. Marketing Science 7, 299-310 (1987)

41. Ajzen, I., Fishbein, M.: Understanding attitudes and predicting social behaviour. PrenticeHall, New Jersey (1980)

42. Loiacono, E.T., Watson, R.T., Goodhue, D.L.: WebQual: An Instrument for Consumer Evaluation of Web Sites. International Journal of Electronic Commerce 11, 51-87 (2007) 